\title{
Inflation and Population Age Structure: The Case of Emerging Economies*
}

\author{
Darya Antonova, European University at St. Petersburg \\ daryaad@gmail.com \\ Yulia Vymyatnina, European University at St. Petersburg \\ yv@eu.spb.ru
}

This paper examines the relationship between inflation and population age structure for emerging market economies. We form an unbalanced panel of data for 21 countries for the period $1950-2017$ and include a number of additional control variables - terms of trade, exchange rate regime, debt-to-GDP ratio, broad money supply growth rates, and PPP-adjusted GDP per capita index. After estimating a variety of model specifications and robustness checks we conclude that the elderly group (65+) in these sample of countries is deflationary, the young group $(0-19)$ shows weak signs of being deflationary, and the working group $(20-64)$ is found to be inflationary. The deflationary effect of the elderly has been found in some studies for OECD countries, but the findings regarding the young group being deflationary and the working group being inflationary are new. Therefore, the question about the general empirical relation between inflation and the population age structure remains unsettled, and it is probable that the relation between population age structure and other macroeconomic variables is different for emerging market economies and for advanced countries.

Keywords: inflation, population Citation: Antonova, D. and age structure, ageing, emerging market economies Vymyatnina, Y. (2018). Inflation and

JEL Codes: E31, E40, O11, P52 Population Age Structure: The Case of Emerging Economies. Russian Journal of Money and Finance, 77(4), pp. 3-25.

doi: $10.31477 /$ rjmf.201804.03

\section{Motivation and literature review}

Since inflation targeting remains the main monetary policy regime among central banks - 40 of them have adopted it, ${ }^{1}$ - understanding of how and why various factors influence inflation as a key concern for monetary policy

\footnotetext{
* The authors are very grateful to the two anonymous referees of the Russian Journal of Money and Finance and to the participants of the First International Research Conference 'Inflation: New Insight for Central Banks,' hosted by the Bank of Russia, for their valuable comments and suggestions.

${ }^{1}$ According to the latest figures of the IMF: IMF (2018). Annual Report on Exchange Arrangements and Exchange Restrictions 2017, April 30. Washington, DC: International Monetary Fund.
} 
authorities. Recent attention to unconventional monetary policies and their results has prompted a search for unconventional explanations of inflation dynamics, especially in developed countries. One of the previously unexamined factors that might influence inflation is demographic trends.

The fact that population dynamics, or, more precisely, changes in the labour force, have a direct influence on the economy's output is widely recognized in growth theory. It is also well understood in macroeconomics that, if a factor of production is suddenly depleted, it will affect its relative price and, through changing production costs, the total output of the economy. The effect of such an event on inflation was mostly disregarded except for the discussion occuring in the early years of World War II (Galbraith, 1941; Hansen, 1941; Keynes, 1940). After that and until the late 1990s there were no studies addressing the link between demographic trends and macroeconomic indicators. A general analysis of how demographic trends influence macroeconomic indicators, including savings rates, inflation, and economic growth was conducted by Lindh (1999), who also addressed the potential of demographic trends for forecasting purposes. Another interesting example suggesting a potential use of demographic trends for macroeconomic forecasting is a very recent study by Buckles et al. (2018), which demonstrates, using the US data, that fertility behaviour might be a leading indicator of economic recessions and not a reaction to the negative economic situation, as was thought earlier. The long-term nature of demographic changes (excluding war periods, natural disasters and similar events that have a striking impact on demographic structure) suggests that any influence of demographic trends on macroeconomics indicators will also be long-term.

The connection between inflation and the population age structure has been often discussed in the context of explaining Japan's prolonged stagnation since the early 1990s through its ageing population, which leads to a deflationary environment and to expectations of decreasing economic growth in the future. Anderson et al. (2014) confirmed that Japan's ageing population introduced deflationary pressures on the economy through lower economic growth expected in the future, falling land prices, and dis-saving behaviour. The latter might be surprising, but in the case of Japan most of the savings were held abroad, and their repatriation into the country resulted in a real exchange rate appreciation, the deflationary effect of which was larger than the inflationary effect of additional spending. Yoon et al. (2014), after considering a group of 30 OECD countries in the period 1960 - 2013, also claimed that population ageing and reduced population growth might exert a sizeable deflationary effect on the economy. These empirical findings have been corroborated by the political economy argument advanced by Bullard et al. (2012), i.e. that - elderly people living on their savings prefer a lower inflation to economic growth and unemployment reduction, and thus consistently vote for political parties that pay more attention to inflation. However, the findings of Juselius and Takáts $(2015,2016 a, 2016 b)$ do not support the political economy 
view, and favour instead a purely economic explanation of the link between inflation and demographic indicators.

Several studies have identified inflationary pressures from older generations: retired people tend to dis-save and stop contributing goods and services to the economy, but continue to demand goods and services. Such effects were confirmed based on the data for the OECD economies by Lindh and Malmberg $(1998,2000)$, Juselius and Takáts (2015, 2016a, 2016b), and Andrews et al. (2018), as well as for specific countries such as Sweden (Lindh, 1999; Bruer, 2002), the US (McMillan and Baesel, 1990) and Australia (Lenehan, 1996). By the same reasoning, the very young should be inflationary, as was found by examining the OECD data in recent studies by Juselius and Takáts (2015, 2016a, 2016b) and Andrews et al. (2018).

The latter two studies use a similar approach and pay close attention to finetuning the age structure, so their results merit a closer look. Juselius and Takáts $(2015,2016 a, 2016 b)$ use a group of 22 OECD countries with data covering the period 1955 - 2010. Apart from using the usual dependency ratio and the division of the population into three different groups - young $(0-19)$, working age $(20-64)$ and elderly (65 and older) - they make use of population polynomials that allow for better capturing the impact of the population structure on inflation, but also economize on the number of estimated coefficients in case of very small age breakdowns (e.g. intervals of 5 years). Their results suggest that the very young $(0-19)$ and the elderly (65+) are inflationary, though the very elderly (presumably $80+$ ) might be deflationary. Since the latter group is rather small in each country, the results are to be interpreted with caution. The working age population is found to be deflationary.

Andrews et al. (2018) find similar results for the same group of countries and the same time period as the previous authors, but they employ an additional method - panel-data VAR - and also break down the group of elderly people into young old $(65-79)$ and older old $(80+)$, in order to study the potentially contradictory effects of the elderly group size on inflation. They conclude that the older cohort of elderly people is deflationary, while the younger old are inflationary, and that the issue in general merits further research. Both this and the previous paper find that the demographic structure explains a large share of inflation variation.

Therefore, existing studies of the relation between inflation and population age structure have found contradictory evidence as regards the influence of the elderly inflationary or deflationary or both - depending on whether the elderly group is divided into further sub-groups. Besides, to the best of our knowledge, all existing empirical studies of this issue focused on OECD countries. While recognizing that demographic indicators, due to the advantage of slow changes, might be attractive for forecasting purposes, it is important to also note that this would only hold true in case of established and well-explained regularities. To be of use for monetary policy conduct, the empirical relation between inflation and population age structure have to be (a) established, and (b) explained using a suitable economic theory. 
With this paper we aim to fill in the gap in the existing literature by examining whether the link between inflation and population age structure exists for emerging economies as well, whether it is the same or different for these countries in comparison with OECD economies, and how the differences, if any, might be explained. We adopt the methodology used in some of the previous studies for OECD countries to check if the results differ for emerging market economies. Addressing this issue would allow us to determine whether the factor of population age structure is relevant for monetary policy conduct in developing countries.

\section{Data}

We use data for 21 emerging market economies: Algeria, Argentina, Belarus, Brazil, Bulgaria, Chile, China, Croatia, Czech Republic, Hungary, India, Kazakhstan, Malaysia, Mexico, Peru, Philippines, Poland, Russia, Saudi Arabia, South Africa, and Ukraine. Some of these countries are usually considered to be more on the 'developed' spectrum - e.g. Poland or the Czech Republic. We consider countries from the former socialist block to be an important part of our sample, since their inflation experience is different from that of most OECD countries, and is closer to some emerging market economies; however, at the same time, their demographic dynamics are closer to those of OECD countries.

We have selected this particular group of countries on the basis of data avialbility. Other countries that we considered - Armenia, Azerbaijan, Cambodia, Columbia, Georgia, Indonesia, Kyrgyzstan, Moldova, Mongolia, Romania, Tajikistan, Thailand, Turkey, and Uzbekistan - either lack some of the data needed, most importantly on GDP and real and/or policy interest rate, or only have certain data used in our analysis availabale for a very short period of time. We considered that having less than 20 years of data for any country will make our results less reliable, and therefore we have opted for a smaller group of countries.

We use annual data on: inflation rate, population age structure data (grouped into age cohorts spanning five years each: $0-4,5-9,10-14$ etc.), real GDP, real interest rate, policy interest rate, terms of trade, debt-to-GDP ratio, exchange rate regime dummies, commodity export dependence dummy, and GDP per capita (PPP). Most of the data cover the period of 1990 - 2017. For some countries (Chile, Argentina, India) we have longer periods of data. Details on the period for which the data are available for each country, as well as on the sources of the data, are provided in Appendix 1.

We used the data collected to calculate output gap (with the Hodrick-Prescott filter applied to the real GDP data), real policy interest rate (policy interest rate corrected for some indicator of inflation expectations - see the next section for details), and three major population groups: young (0 - 19), working $(20-64)$ and old (65+). The sum of young and old divided by working gives us the dependency 
ratio. Using our data index for PPP-adjusted GDP per capita, based on data from the World bank we calculate the ratio of a country's $i$ GDP per capita to the USA GDP per capita (both PPP-adjusted). This index is used as one of our control variables.

At a first step we analyse the data for different countries and compare them with those for OECD countries from the studies of Juselius and Takáts (2015) and Andrews et al. (2018). In the advanced economies sample, inflation, though volatile, remains within the bounds from $-5 \%$ to $+25 \%$; however, in our sample, inflation is much more volatile due to several episodes of hyperinflation followed by a period of high inflation (Figure 1). As Figure 1 suggests, the relation between the age structure of the population and inflation might be non-linear. The largest part of this non-linearity, however, seems to come from different age groups having different dynamics over time and being related to inflation in a different manner.

Figure 1. Inflation variation and dependency ratio

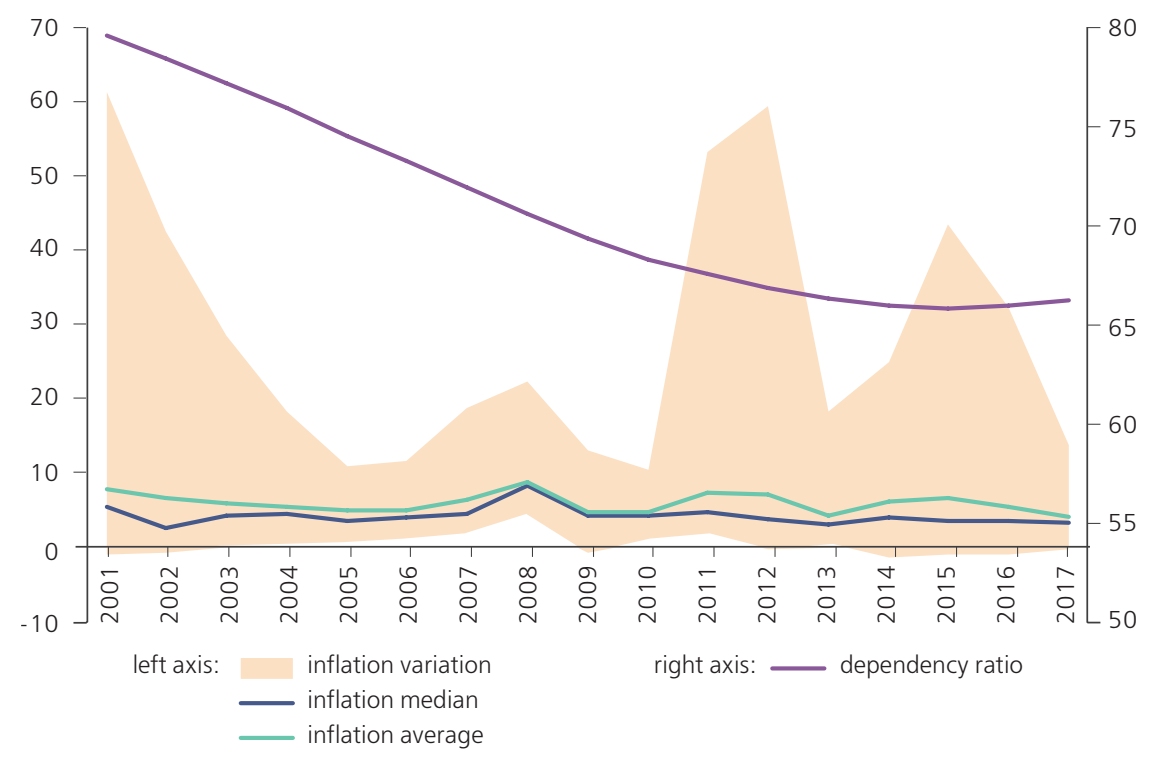

Note: Hyperinflation episodes are excluded.

The simplest indicator of population age structure is the dependency ratio. The typical dependency ratio pattern for OECD countries exhibits a peak around the 1960s - 1970s, with a decline afterwards and an increase in the last $10-15$ years. In our full sample, a slight increase in the dependency ratio is seen only in the last few years (see Figure 2).

A closer analysis of dependency ratios for separate countries demonstrates that most countries in our sample have dependency ratio profiles seemingly close to those of OECD countries (see Figures 1A, 2A, 3A, 4A in Appendix 2). 
These are countries of the former Soviet Union, former socialist countries, and a number of other countries. Several countries have rather different dependency ratio dynamics - e.g. China, Brazil, Croatia, and Malaysia (see Figure 5A in Appendix 2). There is no clear pattern for the dependency ratios seen in our sample of countries - some are closer to advanced economies with an ageing population, while others have an obviously younger population structure. It is interesting to note that India and China, the two most populated economies, have slightly different population dynamics at the end of the sample: in India the dependency ratio is still going down, while in China the ageing has only started to be seen recently. The only common pattern for all countries seems to be the fact that dependency ratio dynamics are mostly driven by the young age group.

Figure 2. Dependency ratio and the breakdown of population (ths.) into three age groups (sample mean)

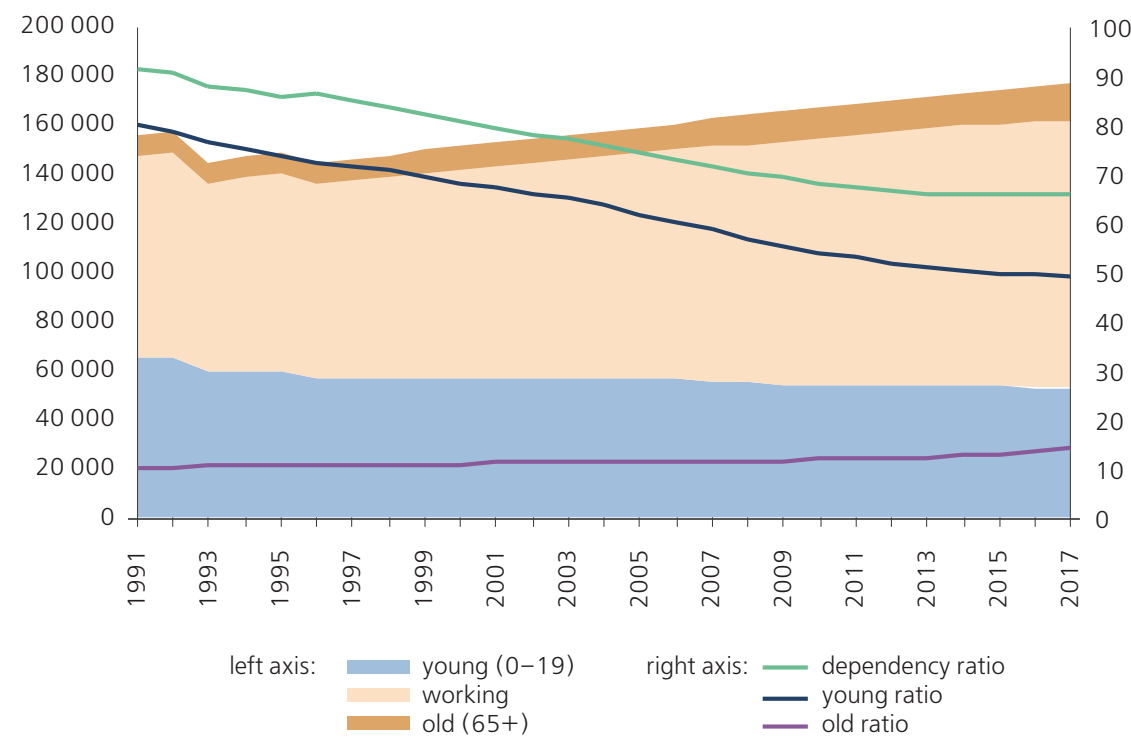

We have omitted hyperinflation episodes from the graphs to make the potential link between inflation and demography more pronounced. However, it is important to stress that the inflation experience of the countries in our sample is very diverse: some countries, such as South Africa or Saudi Arabia had relatively low inflation throughout the whole sample, while a number of other countries had years with inflation of over $1000 \%$, which makes our sample much less homogenous in comparison with the samples used by researchers concentrating on OECD studies. 


\section{Methodology}

Our methodology is defined by two considerations: (1) comparability with previous OECD studies, and (2) data specificity. Our data, unlike those for OECD countries, present much more variation, especially in terms of inflation rates, which are, in almost all cases, clearly non-stationary due to hyperinflation episodes. This means that we have to give more careful consideration to the inflation indicator that we use. Both Juselius and Takáts (2015) and Andrews et al. (2018) mention that demographic indicators, being inertial in nature, should correspond to low-frequency inflation, and they consider annual rates of inflation as being representative of the latter.

It is not very obvious why they did not opt for the use of a frequency filter to extract the low frequency inflation component itself. In our case, with hyperinflation episodes ${ }^{2}$ present, a simple application of any filter does not remove all hyperinflation episodes, and in case of a band-pass, reduces the number of observations. Since for many countries we have only slightly over 20 years of data, we consider using a band-pass filter to be undesirable. The problem of hyperinflation episodes stays if we apply a filter on a 3-year moving average. We did not opt for a 5 -year moving average for the same reason that we discarded the use of the bandpass filter. In the end, we first removed hyperinflation episodes from the series, and then applied a HP-filter to remove the more volatile part of the inflation series.

Due to the constraints imposed by the dataset size, we opted against using population polynomials as in Juselius and Takáts (2015) and Andrews et al. (2018), and decided instead to work with the three population groups of young, working and old. This setup allows us to compare our results with those of Yoon et al. (2014), and with some of the results of Juselius and Takáts (2015) and Andrews et al. (2018). Though we do not aim to replicate the results previously obtained for the OECD countries, we wished to make our results comparable with those of the previous studies, and therefore tried to follow the most common path in our baseline models.

We checked our data for stationarity using panel data stationarity tests (see Appendix 3 for details), and in general our data proved to be stationary. To avoid spurious regressions as much as possible, we have used a 'White period' specification in EViews 10 that computes standard errors that are robust to serial correlation (based on Arellano, 1987, and White, 1980). This allowed us to make inferences from the results that we get even if we have some autocorrelation in residuals. We tested for serial correlation in our results by directly checking the presence of autocorrelation in residuals. ${ }^{3}$ Most of our specifications do not have

\footnotetext{
${ }^{2}$ We consider, somewhat arbitrarily, that hyperinflation starts from $100 \%$ a year. In this we follow the classification suggested, for example, in Acocella (1998, p. 130).

3 We regress residuals on their lagged values and check if the coefficient of such a regression is significantly different from 0 (following the procedure suggested in EViews 10 manual for dynamic panel data (http://www.eviews.com/help/helpintro.html\#page/content/panel-Panel_Estimation_ Examples.html).
} 
autocorrelated residuals. We checked for cross-section dependence by using the Pesaran CD test and found that it is absent in almost all cases at the $10 \%$ level.

We divided our work into two parts: building baseline models for the whole panel and then providing a robustness check by adding various control variables to account for the specifics of the selected groups of countries, or changing some of the indicators used. Our control variables include dummies for the exchange rate regime (1 if different from the free-floating, which is characteristic for OECD countries) and for commodity export dependence, broad money supply growth rate, terms of trade, debt-to-GDP ratio, and index of relative PPP-adjusted GDP per capita.

\section{Baseline models}

Our baseline models consider the relationship (if any) between inflation and various indicators of the population age structure:(1) dependency ratio, (2) dependency ratio split between the young and old population to check if the effects are different, (3) three population groups - young, working and old. During the next stage, we added a real interest rate and output gap as the two most important variables that are likely to affect inflation. At this stage, we used the real interest rate, defined as the lending interest rate (weighted average lending interest rate offered by the banking system to the private non-financial sector) adjusted for inflation, as measured by the GDP deflator. This indicator, supplied by the World Bank, reduces the potential of endogeneity in our models, since the dynamics of the GDP deflator and CPI-based inflation are never fully the same for our group of countries. Therefore, our baseline model has the form:

$$
\begin{gathered}
\pi_{i t}=c+\mu_{i}+\mu_{t}+\beta \operatorname{dep}_{i t}+\varepsilon_{i t} \\
\pi_{i t}=c+\mu_{i}+\mu_{t}+\beta_{1} d e p_{i t}^{y}+\beta_{2} d e p_{i t}^{o}+\varepsilon_{i t} \\
\pi_{i t}=\mu_{i}+\mu_{t}+\beta_{1} s_{i t}^{y}+\beta_{2} s_{i t}^{o}+\beta_{3} s_{i t}^{w}+\varepsilon_{i t}
\end{gathered}
$$

where $\pi_{i t}$ is inflation in country $i$ at time period $t, c$ is a constant (we drop it for the last specification since otherwise we have the three population shares summing up to unity, and with a constant included this results in perfect multicollinearity), $\mu_{i}$ is a cross-section (country) fixed effect, $\mu_{t}$ is a period (time) fixed effect, dep $_{i t}$ is the dependency ratio as defined above, $d e p_{i t}^{y}$ is the dependency ratio for the young dependents (young divided by working), $d e p_{i t}^{o}$ is the dependency ratio of the elderly dependents (old divided by working), $s_{i t}^{y}$ is the share of young in total population, $s_{i t}^{o}$ is the share of old in total population and $s_{i t}^{w}$ is the share of working in the total population.

A closer study of model (3) reveals a problem, however: it is not clear how to interpret the results of such regression, since we cannot conclude that if a share of young increases this will increase or decrease inflation, since the share of the other two groups of population should decrease in that case. We decided to break 
down model (3) into three different models with only two groups in each one. So model 3 became:

$$
\begin{aligned}
& \pi_{i t}=c+\mu_{i}+\mu_{t}+\beta_{1} s_{i t}^{y}+\beta_{2} s_{i t}^{o}+\varepsilon_{i t} \\
& \pi_{i t}=c+\mu_{i}+\mu_{t}+\beta_{1} s_{i t}^{y}+\beta_{3} s_{i t}^{w}+\varepsilon_{i t} \\
& \pi_{i t}=c+\mu_{i}+\mu_{t}+\beta_{2} s_{i t}^{o}+\beta_{3} s_{i t}^{w}+\varepsilon_{i t} .
\end{aligned}
$$

We opted for the fixed effects for the cross-section dimension since the countries in our sample are very different with regard to their political and economic situation. We decided to include time-fixed effects in our specification to account for any possible common events (e.g. the oil crises of 1973 and 1979, the Asian financial crisis of 1997 - 1998, the Great Recession of 2008 - 2009, etc.). To check our reasoning, we verified through the likelihood ratio test that we do need both cross-section and period fixed effects. ${ }^{4}$ Detailed results for models (1) - (3.3) are provided in Table 1.

We also added model (0) in which we regressed our inflation series on the constant, only keeping both country and time fixed effects present. As can be seen from Table 1, model (0) explains around $60 \%$ of variation of the dependent variable. We consider this result as supportive of the fact that we have extracted the part of inflation that might be termed low-frequency, and which can be meaningfully compared with the dynamics of demographic indicators, since adjusted $\mathrm{R}^{2}$ for the regression of the original inflation series on a constant with both types of fixed effects present explained only $22 \%$ of the total variation.

From the results for models (1) - (3.3) in Table 1, we can see that the age structure of the population seems to have some effect on inflation, though results should be treated with caution due to the presence of serial correlation. Results from various regressions reinforce each other: dependents are deflationary, and if they are detached, the elderly group appears to be deflationary, while the younger group is modestly inflationary. If we check this against the results from models (3.1) - (3.3), then the young are inflationary if they increase at the expense of either the old or the working, and the old are deflationary if they increase at the expense of either the young or the working. The results for the working group depend on which group should decrease: they are deflationary if the old decrease and inflationary if the young decrease. For future reference, we use two baseline specifications taken from here - models (2) and (3.1). While they reinforce each other in terms of qualitative results, model (2) is less restrictive in terms of keeping the third group constant, while model (3.1) allows for further comparison with the previous studies.

\footnotetext{
${ }^{4}$ For each of the models $(0)-(21)$ described in this paper, we conducted standard tests on whether we should include country fixed effects, period (time) fixed effects, or, both (LR-test results). In all cases, the tests invariably confirmed that both types of fixed effects should be included. For the sake of brevity, we do not report the details of the results of these tests in the paper, but they are available upon request.
} 
Table 1. Estimation results for models (1) - (3.3). Dependent variable: $\pi_{i t}$

\begin{tabular}{|c|c|c|c|c|c|c|}
\hline & Model 1 & Model 2 & Model 3.1 & Model 3.2 & Model 3.3 & Model 0 \\
\hline$c$ & $0.2260^{* * *}$ & $0.3236^{* * *}$ & $0.3381^{* * *}$ & $-3.9219^{* * *}$ & $0.5290^{* * *}$ & $0.1036^{* * *}$ \\
\hline$d e p_{i t}$ & $-0.1325^{* * *}$ & & & & & \\
\hline$d e p_{i t}^{y}$ & & $0.0576^{*}$ & & & & \\
\hline$d e p_{i t}^{o}$ & & $-2.0364^{* * *}$ & & & & \\
\hline$S_{i t}^{y}$ & & & $0.1910^{*}$ & $4.4509^{* * *}$ & & \\
\hline$S_{i t}^{o}$ & & & $-4.2600^{* * *}$ & & $-4.4509^{* * *}$ & \\
\hline$S_{i t}^{w}$ & & & & $4.2600^{* * *}$ & $-0.1910^{*}$ & \\
\hline Country effect ${ }^{\mathrm{x}}$ & Yes $^{* * *}$ & Yes $^{* * *}$ & Yes $^{* * *}$ & Yes $^{* * *}$ & Yes $^{* *}$ & $\mathrm{Yes}^{* *}$ \\
\hline Time effect ${ }^{\mathrm{x}}$ & Yes $^{* * *}$ & Yes $^{* * *}$ & Yes $^{* * *}$ & Yes $^{* * *}$ & Yes $^{* *}$ & Yes $^{* *}$ \\
\hline $\mathrm{R}^{2}$ adjusted & 0.6060 & 0.6633 & 0.6944 & 0.6944 & 0.6944 & 0.5935 \\
\hline $\begin{array}{l}\text { Number of } \\
\text { observations }\end{array}$ & 826 & 826 & 826 & 826 & 826 & 826 \\
\hline Maximum sample & $1950-2017$ & $1950-2017$ & $1950-2017$ & $1950-2017$ & $1950-2017$ & $1950-2017$ \\
\hline Durbin-Watson statistic & 0.0320 & 0.0370 & 0.0388 & 0.0388 & 0.0388 & 0.0321 \\
\hline F-statistic & 15.4223 & 19.2634 & 22.0587 & 22.0587 & 22.0587 & 14.8446 \\
\hline $\begin{array}{l}\text { Probability of } \\
\text { F-statistic }\end{array}$ & 0.0000 & 0.0000 & 0.0000 & 0.0000 & 0.0000 & 0.0000 \\
\hline Probability of LR test & 0.0000 & 0.0000 & 0.0000 & 0.0000 & 0.0000 & 0.0000 \\
\hline $\begin{array}{l}\text { Probability of cross- } \\
\text { section correlation test }\end{array}$ & 0.0175 & 0.0000 & 0.0000 & 0.0000 & 0.0000 & 0.0085 \\
\hline $\begin{array}{l}\text { Probability of serial } \\
\text { correlation test }\end{array}$ & 0.0000 & 0.0000 & 0.0000 & 0.0000 & 0.0000 & 0.0000 \\
\hline
\end{tabular}

Our results as regards the dependency ratio are at odds with the results of Juselius and Takáts $(2015,2016 a, 2016 b)$, who find for the group of 22 OECD countries that dependents are inflationary, not deflationary. The breakout of the dependency ratio for the young and the old suggest that the overall negative sign for the dependents is explained by the influence of the elderly. This is also at odds with the results of the studies by Juselius and Takáts - according to them it is the very old (a group of $80+$ ) who are deflationary (a result, corroborated by Andrews et al., 2018). Both of these studies treat results for the very old age 
group with care, since the group is comparatively small. For countries in our sample, due to lower longevity, this group is even smaller, so we do not attempt to check for this effect.

Even though we have used a specification that computes standard errors that are robust to serial correlation, we treat the results for models (1) - (3.3) with caution due to the clear presence of serial correlation in residuals. Therefore, we proceeded to check if these were spurious regressions by adding to the selected models (2) and (3.1) variables that are most likely to influence inflation - output gap $\left(y_{i t}\right)$ and real interest rate $\left(r_{i t}\right)$. Real interest rate stands as a proxy for monetary policy, and output gap might influence inflation in the course of the business cycle, especially if the monetary policy did not account correctly for the pressure stemming from the output gap. Such specifications are in line with the studies of Juselius and Takáts $(2015,2016 \mathrm{a}, 2016 \mathrm{~b})$ and Andrews et al. (2018), thus allowing for further comparison. While the output gap is less likely to influence the inflation indicator, corresponding to a more stable part of inflation, persistent mistakes when taking it into account in monetary policy decisions might influence inflation in the longer-term. Adding these two regressors - real interest rate and output gap - might be considered as a crude proxy of either the Phillips curve or of the Taylor rule ('solved' for inflation). Since our main concern in this paper is to check if the population age structure is related in any robust way to inflation, we consider that if population age structure indicators remain significant when all of the other, more conventional, factors of inflation are accounted for, then it may be the case that modelling inflation should account for changes in demography. Model (4) in Table 2 below is for the two dependency ratios, and model (6) for the shares of young and old. Model (8) stands for specification with real interest rate and output gap, but without variables of the age structure.

Since models (4), (6), and (8) have all produced counter-intuitive positive signs of real interest rate coefficients, we have attempted lags of the real interest rate and of the output gap in case of potential endogeneity. Though, as we mentioned earlier, the real interest rate we use is calculated using GDP deflator inflation, thus reducing a potential endogeneity problem, it may still be present. Since monetary policy influences inflation with variable lags that are usually estimated to be about $2-2.5$ years, but might be longer, we included initially six lags of real interest rate and four lags of output gap. Results for specification with the full number of lags are provided in Appendix 4 (models (4.1), (6.1), and (8.1)). In Table 2, below, we report specifications with only those lags of real interest rate that are statistically significant (model (5) for dependency ratios, model (7) for shares, and model (9) for specification without demographic variables). 
Table 2. Estimation results for models (4) - (9). Dependent variable: $\pi_{i t}$.

\begin{tabular}{|c|c|c|c|c|c|c|}
\hline & Model 4 & Model 5 & Model 6 & Model 7 & Model 8 & Model 9 \\
\hline$c$ & $0.2128^{\star * *}$ & $0.2242^{* * *}$ & $0.1758^{* * *}$ & $0.2335^{\star * *}$ & $0.0651^{* * *}$ & $0.0565^{\star * *}$ \\
\hline$d e p_{i t}^{y}$ & -0.0345 & $0.0971^{\star *}$ & & & & \\
\hline$d e p_{i t}^{o}$ & $-0.8318^{* * *}$ & $-0.7042^{* * *}$ & & & & \\
\hline$S_{i t}^{y}$ & & & $0.3116^{* *}$ & 0.0090 & & \\
\hline$s_{i t}^{o}$ & & & $-2.4446^{* * *}$ & $-1.9822^{* * *}$ & & \\
\hline$y_{i t}$ & 0.0006 & & 0.0008 & & 0.0000 & \\
\hline$r_{i t}$ & $0.1292^{* * *}$ & $0.1010^{* * *}$ & $0.1142^{* * *}$ & $0.0917^{\star * *}$ & $0.1367^{\star * *}$ & $0.1043^{* * *}$ \\
\hline$r_{i t-1}$ & & $0.0864^{* * *}$ & & $0.0813^{* * *}$ & & $0.0891^{* * *}$ \\
\hline$r_{i t-3}$ & & $0.0024^{* * *}$ & & $0.0022^{* * *}$ & & $0.0024^{* * *}$ \\
\hline Country effect ${ }^{x}$ & $\operatorname{Yes}^{* * *}$ & Yes $^{* * *}$ & Yes $^{* * *}$ & $\operatorname{Yes}^{* * *}$ & Yes $^{* * *}$ & Yes $^{* * *}$ \\
\hline Time effect ${ }^{\mathrm{x}}$ & Yes $^{* * *}$ & Yes $^{* * *}$ & Yes $^{* * *}$ & $\mathrm{Yes}^{* * *}$ & Yes $^{* * *}$ & Yes $^{* * *}$ \\
\hline $\mathrm{R}^{2}$ adjusted & 0.6594 & 0.7265 & 0.6851 & 0.7371 & 0.6453 & 0.7094 \\
\hline $\begin{array}{l}\text { Number of } \\
\text { observations }\end{array}$ & 494 & 476 & 494 & 476 & 494 & 476 \\
\hline Maximum sample & $1960-2016$ & $1954-2017$ & $1960-2016$ & 1954-2017 & $1960-2016$ & $1954-2017$ \\
\hline Durbin-Watson statistic & 0.2368 & 0.7351 & 0.2147 & 0.6873 & 0.2432 & 0.7830 \\
\hline F-statistic & 12.9319 & 15.3353 & 14.4068 & 16.1315 & 12.4994 & 14.4863 \\
\hline Probability of F-statistic & 0.0000 & 0.0000 & 0.0000 & 0.0000 & 0.0000 & 0.0000 \\
\hline Probability of LR test & 0.0000 & 0.0000 & 0.0000 & 0.0000 & 0.0000 & 0.0000 \\
\hline $\begin{array}{l}\text { Probability of cross- } \\
\text { section correlation test }\end{array}$ & 0.5561 & 0.2071 & 0.4737 & 0.4184 & 0.0752 & 0.5305 \\
\hline $\begin{array}{l}\text { Probability of serial } \\
\text { correlation test }\end{array}$ & 0.0000 & 0.0862 & 0.0000 & 0.0736 & 0.0000 & 0.0859 \\
\hline
\end{tabular}

${ }^{*}$ denotes significance at $10 \%$ level, ${ }^{* *}$ denotes significance at $5 \%$ level, ${ }^{* * *}$ denotes significance at $1 \%$ level.

${ }^{x}$ denotes that for this type of fixed effects it was verified that it should be present in the model, and that both types of fixed effects jointly should be present in the model.

As can be seen from Table 2, adding demographic structure indicators improves slightly the goodness of fit (compare models (4) - (7) with models (8) - (9)). It is also clear that the output gap is not statistically significant, and its removal improves the fit of the regression (compare model (4) against (5), and model (6) against (7)). This is not a very surprising result for our sample, since the countries in question went through several periods of political and economic instability, often accompanied by hyperinflation episodes, thus blurring the relation between output and inflation until the situation fully stabilizes. It might also be the case that a simple HP-filter does not really remove the cycles from the GDP data (Aguiar and Gopinath, 2007). However, we consider that the most conventional method of obtaining the output gap is suitable for our purpose, i.e. that of establishing the presence of certain empirical regularities. Yoon et al. (2014) mention that the very concept of an output gap depends on the method used to measure the potential output, and the latter clearly depends on the population age structure. 
The real interest rate is significant in all cases, and it is positively related to inflation indicator. Adding lags of the real interest rate does not change the result; all significant lags have positive coefficients. While this is contrary to what is theoretically expected, it can be explained by the specifics of the countries in our sample. For countries that are dependent on natural resources exports (a third of countries in our sample are resource-dependent according to UNCTAD - Algeria, Argentina, Chile, Peru, Saudi Arabia, Kazakhstan, and Russia) and that use 'dirty float' policies to stabilize their exchange rates (which is the case for these countries for most of our sample period), an increase in the costs of domestic borrowing does not necessarily decrease output and inflation pressures. Indeed, it is often the result of an attempt by monetary authorities to reduce inflationary pressures and stabilize exchange rates at the same time. Appreciation pressure in situations of high-resource prices results in the central bank buying foreign currency to keep the nominal exchange rate at a certain level, and this contributes to inflation (Charemza et al., 2009; Sosunov and Zamulin, 2007). This hypothesis calls in for additional control variables that we use later on, e.g. exchange rate regime dummy, commodity export dependence dummy, and terms of trade index. Another explanation of this positive relation between real interest rate and inflation is that the cause and effect are reveresed, i.e. that in periods of high inflation the nominal policy rate is high, thus pushing real interest rates up. There might be several rounds of such policy rate increases coinciding with periods of high inflation, accounting for the positive connection between inflation and real interest rates.

Comparing models (2) and (3.1) to models (4) - (5) and (6) - (7), respectively, we see that as regars the absolute size of the demographic indicators, coefficients becomes smaller when the real interest rate and output gap are included, however the sign stays the same. It is interesting to note that the deflationary effects of the old group are more pronounced and always highly statistically significant, regardless of whether we consider the share of this age group relative to the total population or relative to the working population. This is in contrast with the findings of both Juselius and Takáts (2015, 2016a, 2016b) and Andrews et al. (2018), who find that the young group is inflationary (as is weakly suggested in our case) and highly statistically significant, while the elderly are also inflationary, and only the very old are deflationary. However, our results concerning the deflationary effect of the old group are in line with the results of Yoon et al. (2014), whose main concern is that significant deflationary pressure from the elderly might make higher inflation targets unattainable.

\section{Robustness checks}

Before proceeding to add controls accounting for the specific features of the studied group of countries, we perform a robustness check of our results by using different indicators of the real interest rates. Since the relevance of the indicator that we use - the lending rate corrected for inflation using GDP deflator - for the 
monetary policy and, hence, inflation, might be questioned, we use the nominal policy interest rate and correct it for expected inflation calculated in three different ways. The first two ways acknowledge the fact that inflation in developing and emerging economies is characterized by high inertia (Crowley, 2010; Edwards, 1998; Chopra, 1985). In the first case we mode individual inflation series as AR(1) processes and use one-step static forecasts from these $\mathrm{AR}(1)$ models to get the expected inflation (models (10) and (11)). In the second case we use a very crude rule for calculating expected inflation by assuming adaptive expectations with a simple rule of expecting $90 \%$ of today's inflation for the next period (models (12) and (13)). In the third case we rely on the fact that inflation expectations are, effectively, based on our previous experience of inflation (Trehan, 2010), and we use Allais' method for specifying inflation 'perceptions' - as he called them - following the algorithm outlined in Barthalon (2014) (models (14) and (15)). We are aware that none of these ways of extracting inflation expectations from the data are ideal. However, they are simple to produce and allow for various ways of defining the real policy interest rate and robustness check. The results of the robustness checks of models (5) and (7) with three different options for the real interest rate are provided in Table 3.

As can be seen from Table 3, our results presented in Table 2 are robust to the changing real interest rate indicator in the baseline models (5) and (7), which include the real interest rate and its lags. Mostly, regressors retain their relative importance. Except for coefficients for the share of the young or for the dependency ratio of the young, which becomes insignificant in some modifications, coefficients are about the same in absolute size and retain their signs and significance.

We proceed with adding variables that might be relevant for inflation dynamics in the countries under consideration: broad money growth rates $\left(\Delta m_{i t}\right)$, exchange rate regime dummy (with 1 corresponding to some sort of exchange rate manipulation and 0 otherwise - exr $\left.{ }_{i t}\right)$, terms of trade index $\left(t t r_{i t}\right)$, debt to GDP ratio $\left(d e b t_{i t}\right)$, and GDP PPP index $\left(y_{-} p p p_{i t}\right){ }^{5}$ We also tried to include a dummy for the commodity export dependence, but this resulted in a near-singular matrix response regardless of the estimation method used. Since we could not get data on the share of commodities in exports for our sample of countries based on the same method of calculation and for a reasonable period of time (at least 20 years), we had to drop this control variable. Growth rates of monetary aggregates could partially explain the inflation dynamics during periods of hyperinflation and subsequent adjustment. Though we have removed hyperinflation episodes from our inflation indicators, money supply growth rates could still be important in explaining inflation dynamics. Yoon et al. (2014) use the growth rate of M2 as a control variable and find it statistically significant. In our case, across all countries, we obtained only broad money (broader money aggregate compared to M2) growth rates.

\footnotetext{
${ }^{5}$ The authors are very grateful to the anonymous referees for suggesting a comprehensive list of control variables on top of our own ideas.
} 
Table 3. Estimation results for models (10) - (15). Dependent variable: $\pi_{i t}$

\begin{tabular}{|c|c|c|c|c|c|c|}
\hline & Model 10 & Model 11 & Model 12 & Model 13 & Model 14 & Model 15 \\
\hline$c$ & $0.1317^{\star \star \star}$ & $0.1331^{\star * *}$ & $0.1713^{\star * *}$ & $0.1714^{\star * *}$ & $0.2311^{\star * *}$ & $0.2250^{* * *}$ \\
\hline$d e p_{i t}^{y}$ & $-0.0664^{*}$ & & $-0.0688^{*}$ & & $-0.0914^{*}$ & \\
\hline$d e p_{i t}^{o}$ & $-0.2649^{*}$ & & $-0.4826^{* * *}$ & & $-0.6783^{* * *}$ & \\
\hline$S_{i t}^{y}$ & & 0.0417 & & 0.0696 & & 0.0929 \\
\hline$S_{i t}^{o}$ & & $-1.0705^{* * *}$ & & $-1.5468^{* * *}$ & & $-2.0614^{* * *}$ \\
\hline$r_{i t}$ & $0.1368^{* * *}$ & $0.1304^{\star * *}$ & $0.1222^{* * *}$ & $0.1133^{* * *}$ & $0.0391^{*}$ & 0.0322 \\
\hline$r_{i t-1}$ & $0.1035^{* * *}$ & $0.0992^{* * *}$ & $0.0661^{* * *}$ & $0.0638^{\star * *}$ & 0.0169 & 0.0156 \\
\hline$r_{i t-3}$ & $0.0045^{* * *}$ & $0.0042^{* * *}$ & $0.0046^{* * *}$ & $0.0043^{* * *}$ & $0.0022^{* * *}$ & $0.0019^{* * *}$ \\
\hline Country effect ${ }^{x}$ & Yes $^{\star * *}$ & $\operatorname{Yes}^{* * *}$ & Yes $^{* * *}$ & Yes $^{* *}$ & $\mathrm{Yes}^{\star *}$ & Yes $^{* *}$ \\
\hline Time effect ${ }^{\mathrm{x}}$ & Yes $^{* * *}$ & Yes $^{* * *}$ & Yes $^{* * *}$ & Yes $^{* *}$ & Yes $^{* *}$ & Yes $^{* *}$ \\
\hline $\mathrm{R}^{2}$ adjusted & 0.7848 & 0.7887 & 0.7434 & 0.7521 & 0.6907 & 0.7058 \\
\hline $\begin{array}{l}\text { Number of } \\
\text { observations }\end{array}$ & 476 & 476 & 476 & 476 & 476 & 476 \\
\hline Maximum sample & $1954-2017$ & $1954-2017$ & $1954-2017$ & $1954-2017$ & 1954-2017 & $1954-2017$ \\
\hline Durbin-Watson statistic & 0.6329 & 0.5989 & 0.5543 & 0.5313 & 0.2766 & 0.2632 \\
\hline F-statistic & 20.6870 & 21.1511 & 16.6393 & 17.3753 & 13.0562 & 13.9504 \\
\hline Probability of F-statistic & 0.0000 & 0.0000 & 0.0000 & 0.0000 & 0.0000 & 0.0000 \\
\hline Probability of LR test & 0.0000 & 0.0000 & 0.0000 & 0.0000 & 0.0000 & 0.0000 \\
\hline $\begin{array}{l}\text { Probability of cross- } \\
\text { section correlation test }\end{array}$ & 0.5105 & 0.4705 & 0.7125 & 0.6949 & 0.2274 & 0.1986 \\
\hline $\begin{array}{l}\text { Probability of serial } \\
\text { correlation test }\end{array}$ & 0.0687 & 0.0613 & 0.0548 & 0.0512 & 0.0000 & 0.0000 \\
\hline
\end{tabular}
correlation test

${ }^{*}$ denotes significance at $10 \%$ level, ${ }^{* *}$ denotes significance at $5 \%$ level, ${ }^{* *}$ denotes significance at $1 \%$ level.

${ }^{x}$ denotes that for this type of fixed effects it was verified that it should be present in the model, and that both types of fixed effects jointly should be present in the model.

We added the exchange rate regime dummy, since a number of countries in our sample have been involved in managing exchange rates for a considerable part of the sample period, and such practices tend to affect inflation. To capture the fact that inflation might also be influenced by current account pressures, we include terms of trade as another control variable. Yoon et al. (2014) use this control variable for OECD countries, and find it to be negative and statistically significant. Debt-to-GDP ratio might be an important factor adding to inflation for the countries we considered, since in case of prolonged budget deficits and growing indebtedness of the government, central banks in these countries could have been called in for help, thus exerting direct inflation pressure. A similar control variable - budget balance change - was used for OECD countries in Yoon et al. (2014), who found it to have a statistically significant and positive effect on inflation. 
We also added an index that relates the country's GDP per capita based on PPP to that of the USA. This allows us to capture the standards of living of the country in relation to an external criterion, and to verify that the relation between inflation and population age structure is not a spurious one. We opted for an index rather than PPP-adjusted GDP per capita to ensure that all variables in our regressions have similar units of measurement by being shares of a unit.

Table 4 shows the first results for the model with two dependency ratios with the full list of control variables and the most parsimonious specification with removed insignificant regressors (models (16) and (17)), and then results for the model with the two shares - young and old - also with the full list of controls and the most parsimonious specification (models (18) and (19)). We have also verified that our results of models (16) - (19) are robust to the choice of real interest rate indicator by re-estimating these models by using the same options of real interest rate as in Table 3. Results are available upon request.

As can be seen from Table 4, inclusion of a full control list resulted in a substantial decrease in the observations included, due to a reduced period of data availability. Besides, we could not obtain data on debt-to-GDP ratio for a third of our sample. Therefore, even though this control variable is significant, we have opted to drop it and concentrate on other control variables, since the excessively high level of debt might influence inflation through the interest rates that are included in our regressions. Broad money supply growth rates are completely unrelated to our inflation indicator. We consider this an additional confirmation that we have managed to extract the low-frequency inflation corresponding to long-term trends, since the latter should be related not so much to monetary factors as to more fundamental ones. It might be noted that the regime of control over the exchange rate resulted in lower inflation for the countries in our sample, meaning that the exchange rate served as a nominal anchor helping to stabilize the economy (Edwards, 2011). Terms of trade in the final specification are slightly inflationary, which is explained by the fact that at least a third of the countries included in our sample are dependent on commodity exports; and higher resource prices, increasing terms of trade index, exert inflationary pressure. This is in contrast with the findings of Yoon et al. (2014) for OECD countries, which is also to be expected, since OECD countries are mostly net importers.

The relative level of GDP per capita does play a role in inflation dynamics for the countries in our sample: the higher standard of living corresponds to lower inflation. This is a logical result, since lower inflation usually produces a more stable economic environment, which allows for higher economic growth and better standards of living. However, presence of the standard of living indicator does not make variables reflecting population age structure totally irrelevant - while the share of the young and the young dependency ratio both become insignificant, the share and dependency ratio of the old remain statistically significant and retain a negative sign. 
Table 4. Estimation results for models (16) - (21). Dependent variable: $\pi_{i t}$

\begin{tabular}{|c|c|c|c|c|c|c|}
\hline & Model 16 & Model 17 & Model 18 & Model 19 & Model 20 & Model 21 \\
\hline$c$ & $0.2181^{* * *}$ & $0.3292^{* * *}$ & $0.3888^{* * *}$ & $0.3679^{* * *}$ & $0.0974^{\star * *}$ & -0.0283 \\
\hline$d e p_{i t}^{y}$ & $-0.1391^{\star *}$ & -0.0368 & & & -0.0567 & \\
\hline$d e p_{i t-10}^{y}$ & & & & & $0.2126^{\star * *}$ & \\
\hline$d e p_{i t}^{o}$ & $-0.3635^{*}$ & $-0.7510^{* * *}$ & & & $-0.2720^{\star * *}$ & \\
\hline$d e p_{i t-10}^{o}$ & & & & & $-0.5283^{* * *}$ & \\
\hline$S_{i t}^{y}$ & & & $-0.6964^{* * *}$ & -0.0840 & & $-0.1762^{\star *}$ \\
\hline$S_{i t-10}^{y}$ & & & & & & $0.5961^{* * *}$ \\
\hline$S_{i t}^{o}$ & & & $-0.7855^{* *}$ & $-1.6814^{* * *}$ & & -0.1356 \\
\hline$S_{i t-10}^{o}$ & & & & & & $-0.5308^{\star *}$ \\
\hline$y_{i t}$ & 0.0009 & & $0.0009^{*}$ & & & \\
\hline$r_{i t}$ & $0.0704^{* *}$ & $0.0492^{\star *}$ & $0.0701^{* *}$ & $0.0488^{* *}$ & $0.1450^{* * *}$ & $0.1559^{* * *}$ \\
\hline$r_{i t-1}$ & $0.0450^{*}$ & $0.0607^{* * *}$ & $0.0470^{* *}$ & $0.0595^{\star * *}$ & $0.1127^{* * *}$ & $0.1203^{* * *}$ \\
\hline$r_{i t-3}$ & $0.0445^{\star * \star}$ & $0.0357^{\star \star}$ & $0.0455^{* * *}$ & $0.0349^{* *}$ & & \\
\hline$r_{i t-4}$ & -0.0382 & & $-0.0379^{*}$ & & & \\
\hline$\Delta m_{i t}$ & 0.0000 & & 0.0000 & & & \\
\hline$e x r_{i t}$ & 0.0011 & $-0.0305^{* * *}$ & -0.0004 & $-0.0272^{* * *}$ & & \\
\hline$t t r_{i t}$ & -0.0077 & $0.0244^{* * *}$ & -0.0079 & $0.0235^{* * *}$ & $0.0128^{* * *}$ & $0.0108^{* * *}$ \\
\hline$d e b t_{i t}$ & $0.0525^{\star * *}$ & & $0.0561^{\star * *}$ & & & \\
\hline$y_{-} p p p_{i t}$ & $-0.1127^{\star}$ & $-0.4438^{* * *}$ & $-0.1301^{\star *}$ & $-0.4271^{* * *}$ & & \\
\hline$y_{-} p p p_{i t-1}$ & & & & & $-0.2396^{* * *}$ & $-0.1791^{* * *}$ \\
\hline Country effect ${ }^{\mathrm{x}}$ & Yes $^{* * *}$ & Yes $^{* * *}$ & Yes $^{* * *}$ & $\operatorname{Yes}^{* * *}$ & $\operatorname{Yes}^{* * *}$ & $\operatorname{Yes}^{* * *}$ \\
\hline Time effect ${ }^{x}$ & $\mathrm{Yes}^{* *}$ & $\mathrm{Yes}^{* *}$ & Yes $^{* * *}$ & $\mathrm{Yes}^{* *}$ & Yes $^{* * *}$ & Yes $^{* * *}$ \\
\hline $\mathrm{R}^{2}$ adjusted & 0.9504 & 0.7578 & 0.9531 & 0.7622 & 0.9076 & 0.9039 \\
\hline $\begin{array}{l}\text { Number of } \\
\text { observations }\end{array}$ & 149 & 385 & 149 & 385 & 374 & 374 \\
\hline Maximum sample & $1990-2016$ & $1990-2016$ & $1990-2016$ & $1990-2016$ & $1991-2016$ & $1991-2016$ \\
\hline Durbin-Watson statistic & 0.7053 & 0.5764 & 0.7431 & 0.5644 & 0.6285 & 0.6229 \\
\hline F-statistic & 58.8464 & 23.2489 & 62.4273 & 23.7899 & 70.1053 & 67.1899 \\
\hline Probability of F-statistic & 0.0000 & 0.0000 & 0.0000 & 0.0000 & 0.0000 & 0.0000 \\
\hline Probability of LR test & 0.0000 & 0.0000 & 0.0000 & 0.0000 & 0.0000 & 0.0000 \\
\hline $\begin{array}{l}\text { Probability of cross- } \\
\text { section correlation test }\end{array}$ & $\mathrm{N} / \mathrm{A}$ & 0.0244 & N/A & 0.0250 & 0.0094 & 0.0175 \\
\hline $\begin{array}{l}\text { Probability of serial } \\
\text { correlation test }\end{array}$ & 0.0841 & 0.0516 & 0.0732 & 0.0493 & 0.0231 & 0.0392 \\
\hline
\end{tabular}
correlation test

${ }^{*}$ denotes significance at $10 \%$ level, ${ }^{* *}$ denotes significance at $5 \%$ level, ${ }^{* * *}$ denotes significance at $1 \%$ level.

${ }^{x}$ denotes that for this type of fixed effects it was verified that it should be present in the model, and that both types of fixed effects jointly should be present in the model. 
Interestingly, in both cases of population age structure representation dependency ratios or shares of young and old in the population - we end up with the same most parsimonious specification in terms of control regressors. This suggests similar dynamics of the share of young in the total population and the ratio of young to the working population, with the same applying to the group of old. It should be mentioned that, in comparison with previous results without additional controls, young dependents become not significant, and that the sign changes from children being inflationary to them being deflationary, though with a smaller absolute size of a coefficient in comparison with the old group. This is in contrast with studies of Juselius and Takáts (2015, 2016a, 2016b) and Andrews et al. (2018) who find the young group to be consistently inflationary. There are no direct counterparts to these results in other studies.

We consider the results obtained from model (17) and model (19) to be the most reliable in terms of their quality (though with some reservations about their cross-section and serial correlations), as they capture the influence of monetary policy on inflation (through the dummy for exchange rate regime, and real interest rate) and that of the external factors (through the terms of trade index), they account for countries' specificity (through country fixed effects), and for any common temporary shocks that these countries might have had (through period fixed effects). The old group is deflationary - it is significant in all models, and the effect is always deflationary, regardless of which particular specification is chosen. This is in line with the results of Yoon et al. (2014) for OECD countries, and is partly corroborated by the evidence from Juselius and Takáts $(2015,2016$ a, 2016b) and Andrews et al. (2018), though only for the very old group and with some reservations. It is more difficult to make a definite statement about the young group, since in regressions without additional controls they demonstrate an inflationary effect, while in regression with additional controls there is weak evidence for them being deflationary. While we have not calculated the working group directly in our regressions, we can deduce that if this group's relative size increases at the expense of the other two groups, the net result will be inflationary (due to a lower deflationary effect from the old and, possibly, the young).

The fact that the elderly in our group of countries are deflationary rather than inflationary can be explained by specific features of these countries. These countries are usually characterized by low savings, low pensions, and high levels of poverty among the elderly (see e.g. Barrientos et al., 2003). These factors explain why there is no inflationary effect from the elderly - they cannot spend their savings, and they usually receive many of the services they need from within their households. This is in line with the fact that emerging countries in our sample are characterized by higher levels of traditional values, and concentration on survival (Dülmer et al., 2015), including close family ties, with a much higher proportion of grown-up children living with parents (Szołtysek and Poniat, 2018). This makes it likely that children are raised with the help of family members 
(grandparents baby-sitting, second-hand goods for children handed down, etc.), making children-related consumption relatively small and providing arguments in favour of the deflationary effects of the young group.

An inflationary effect from the working group might be in part explained through the 'Duesenberry effect'. Davies mentions population inflation as one of the important factors influencing both inflation and monetary policy conduct in poorer countries of the 'South and East' as he calls them (Davies, 2002, pp. 6-7). He suggests that inflationary pressures of the relatively young population of the developing countries striving for consumption patterns of a higher social class ('Duesenberry effect') make the conduct of monetary policy much more difficult compared to the developed countries of the global North and West, where population pressures are less pronounced. Our results provide tentative support for the existence of the 'Duesenberry effect' which is in line with the results of the World Values Survey, suggesting that a higher share of young people in emerging economies considers being rich as important. ${ }^{6}$

The specifications that have been tried so far did not allow for studying the dynamic effects of demographic changes on inflation. While adding lags of the dependent variable is a desirable way to address the issue, this would require finding an instrument for inflation, which is a difficult task and might be better addressed in further studies. We have opted to check if the lags of our population age structure variables add something to the picture of inter-relations between inflation and demography. We have added to models (17) and (19) 10 lags of either shares or dependency ratios of both young and old groups. In Table 4 models (20) and (21) present the most parsimonious specifications excluding insignificant regressors. While the quality of these regressions is also compromised by the presence of serial and cross-section correlations, we rely on the use of standard errors that are robust to serial correlation. We have opted not to use more than 10 lags since this would decrease the size of the sample and might further compromise the validity of the results.

As can be seen from models (20) and (21), the old group is deflationary both at present, as well as 10 years ago, while the latter has a larger negative coefficient, implying that the deflationary effect of the elderly is consistent over time. In a sense, this might be viewed as confirming the tentative results of Juselius and Takáts (2015, 2016a, 2016b) and Andrews et al. (2018) that the very old group is deflationary. An interesting result from models (20) and (21) is that while the present young group seems to be deflationary, the young group of 10 years ago proves to be inflationary. Since within 10 years roughly half of this group would have entered the working group, this indirectly confirms the inflationary effect of the working group. While models (20) and (21) provide some hints about the dynamics between inflation and population age structure, a more thorough and better-structured investigation of the issue is needed, and constitutes a good topic for further research.

\footnotetext{
${ }^{6}$ Results of wave 6 at http://www.worldvaluessurvey.org/WVSOnline.jsp
} 


\section{Concluding remarks}

The purpose of this paper has been to investigate the existence and nature of a link between inflation and population age structure for a group of emerging market economies comprised of 21 countries, and to compare the results with those from the previous studies of the same issue for OECD countries. Our selection of countries was based mostly on the basis of data availability, since we tried to get at least 20 years of data for all countries in our sample.

Since in our sample a number of countries had hyperinflation episodes, we had to adjust the inflation indicator by excluding those episodes, and by filtering out the cyclical component to concentrate on the more stable component of inflation, which could be deemed as corresponding to low-frequency inflation. This indicator was proved to be stationary and, in our view, captures the more stable and long-term oriented part of inflation. This contrasts our study with those focused on OECD countries, where annual inflation was considered as corresponding to low-frequency inflation without additional adjustments.

Another difference of our study from those for OECD countries is the set of control variables used. They include terms of trade, exchange rate regime characteristics, debt-to-GDP ratio, broad money supply growth rates, and PPPadjusted GDP per capita index. All these factors have a direct or indirect bearing on the monetary policy conduct of the countries in our sample, and have the potential to influence inflation.

We have found that variables describing population age structure are jointly significant in most settings, and this is in line with the previous OECD studies. Our main result is that the old group (65+) is deflationary, when considering both the share of this group in the total population, and its dependency ratio. The effect is consistent across various model specifications. This corresponds well to the conclusions of Yoon et al. (2014), but is not exactly the same as the results of Juselius and Takáts $(2015,2016 a, 2016 b)$ and Andrews et al. (2018). The explanation for the elderly being deflationary in our study involves such specific features of the group of the countries we studied as low savings, low pensions, higher levels of traditional values and concentration on survival. Unlike many OECD countries, elderly people in emerging markets are usually at the bottom of income distribution, so it is not surprising that they are not inflationary.

We have found weak signs that the young group is deflationary as well, though the effect is not so consistent across different specifications, and it is not always significant at $10 \%$ level. It is not surprising that the young are weakly deflationary in the selected group of countries, again due to higher levels of traditional values and a high level of family ties, implying that people tend to live in extended families, providing free childcare and elderly care.

An indirect conclusion stemming from our results concerning the working group of the population is that this group tends to be inflationary, which is in contrast with the results found for the OECD countries. This can be explained by the 
fact that, in our sample, the working group composition is skewed towards younger people, for whom the 'Duesenberry effect' - the desire to imitate upper classes' consumption patterns - might be at work, as is confirmed by the results from the World Values Survey.

Since our results are different to some of the conclusions of those focusing on OECD countries, the issue of the empirical relation between inflation and the population age structure is far from being resolved. Further studies might concentrate on the relationship between the population age structure and other macroeconomic indicators, e.g. savings rate dynamics and economic growth rates, for emerging market economies, and compare the results with those obtained for advanced countries. Another important line for further inquiry is an examination of the dynamic effects of population age structure on inflation, both for emerging market economies and the OECD countries. An accumulation of evidence concerning empirical regularities of this sort should be helpful in developing a suitable macroeconomic theory that accounts for the composition of the population in a given country.

Finally, we would like to stress that the growing share of the elderly in most of the countries, including emerging economies, might become a concern for monetary policy conduct, since this group has a negative relation to inflation and thus might present problems when an expansionary monetary policy is needed. It is important to highlight that we consider our results as having qualitative rather than quantitative value, in showing the relative importance of various age groups for inflation dynamics.

Appendices are available at www.cbr.ru/eng/money-and-finance; dx.doi.org/10.31477/rjmf.201804.03

\section{References}

Acocella, N. (1998). The Foundations of Economic Policy: Values and Techniques. Cambridge: Cambridge University Press.

Aguiar, M. and Gopinath, G. (2007). Emerging Market Business Cycles: The Cycle is the Trend. Journal of Political Economy, 115(1), pp. 69-102.

Anderson, D., Botman, D. and Hunt, B. (2014). Is Japan's Population Aging Deflationary? IMF Working Paper, 14/139.

Andrews, D., Oberoi, J., Wirjanto, T. and Zhou, Ch. (2018). Demography and Inflation: an International Study. North American Actuarial Journal. doi: 10.1080/10920277.2017.1387572.

Arellano, M. (1987). Computing Robust Standard Errors for Within-group Estimators. Oxford Bulletin of Economics and Statistics, 49(4), pp. 431-434.

Barrientos, A., Gorman, M., and Heslop, A. (2003). Old Ae Poverty in Developing Countries: Contributions and Dependence in Later Life. World Development, 31(3), pp. 555-570. 
Barthalon, E. (2014). Uncertainty, Expectations and Financial Instability: Reviving Allais' Lost Theory of Psychological Time. New-York: Columbia University Press.

Bruer, M. (2002). Can Demography Improve Inflation Forecasts? The case of Sweden. Uppsala: Nationalekonomiska Institutionen Working Paper Series, N 4.

Buckles, K., Hungerman, D. and Lugauer, S. (2018). Is Fertility a Leading Economic Indicator? NBER Working Paper, N 24355.

Bullard, J., Garriga, C. and Walker, C. J. (2012). Demographics, Redistribution, and Optimal Inflation. Federal Reserve Bank of St. Louis Review, November/December 2012, 94(6), pp. 419-39.

Charemza, W., Makarova, S., Prytula, Ya., Raskina, J.; Vymyatnina, Yu.(2009). A Small Forward-Looking Inter-Country Model (Belarus, Russia and Ukraine). Economic Modelling, 26(6), pp. 1172-1183.

Chopra, A. (1985). The Speed of Adjustment of the Inflation Rate in Developing Countries: A Study of Inertia. IMF Staff Papers, 32(4), pp. 693-733.

Crowley, J. (2010). Commodity Prices and Inflation in the Middle East, North Africa, and Central Asia. IMF Working Paper, N 10/135.

Davies, G. (2002). A History of Money from Ancient Times to the Present Day. Cardiff: University of Wales Press.

Dülmer, H., Inglehart, R. and Welzel, C. (2015). Testing the Revised Theory of Modernization: Measurement and Explanatory Aspects. World Values Research, 8(2), pp. 68-100.

Edwards, S. (1998). Two Crises: Inflationary Inertia and Credibility. The Economic Journal, 108(448), pp. 680-702.

Edwards, S. (2011). Exchange Rates in Emerging Countries: Eleven Empirical Regularities from Latin America and East Asia. NBER Working Paper, N 17074.

Galbraith, J. K. (1941). The Selection and Timing of Price Controls. Review of Economic Statistics, 23(2), pp. 82-85.

Hammonds, G. (2012). State of the Art of Inflation Targeting. London: Bank of England.

Hansen, A. (1941). Defense Financing and Inflation Potentialities. Review of Economic Statistics, 23(1), pp. 1-7.

Juselius, M. and Takáts, E. (2015). Can Demography Affect Inflation and Monetary Policy? BIS Working Papers, N 485.

Juselius, M. and Takáts, E. (2016a). The Age Structure-Inflation Puzzle. Bank of Finland Research Discussion Paper, March 1.

Juselius, M., and Takáts, E. (2016b). Age and Inflation. Finance \& Development (IMF), 53(1).

Keynes, J.M. (1940). How to Pay for the War. London: Macmillan.

Lenehan, A. J. (1996). The Macroeconomic Effects of the Postwar Baby Boom: Evidence from Australia. Journal of Macroeconomics, 18(1), pp. 155-69.

Lindh, T. (1999). Medium-term Forecasts of Potential GDP and Inflation Using Age Structure Information. Sveriges Riksbanks Working Paper, N 99. 
Lindh, T. and Malmberg, B. (1998). Age Structure and Inflation - a Wicksellian Interpretation of the OECD data. Journal of Economic Behavior Organization, 36(1), pp. 19-37.

Lindh, T. and Malmberg B. (2000). Can Age Structure Forecast Inflation Trends? Journal of Economics and Business, 52(1/2), pp. 31-49.

McMillan, H. M. and Baesel, J. B. (1990). The Macroeconomic Impact of the Baby Boom Generation. Journal of Macroeconomics, 12(2), pp. 167-95.

Sosunov, K. and Zamulin, O. (2007). Monetary Policy in an Economy Sick with Dutch Disease. CEFIR/NES Working Paper, N 101.

Szoltysek, M. and Poniat, R. (2018). The Power of the Family: New Data Reveal the Role of the Historical Family as the Instigator of Disparate and Lasting Developmental Trajectories. World Values Research, 10(1), pp. 1-39.

Trehan, B. (2010). Survey Measures of Expected Inflation and the Inflation Process. Federal Reserve Bank of San Francisco Working Paper Series, N 2009-10.

White, H. (1980). A Heteroscedasticity-consistent Covariance Matrix Estimator and a Direct Test for Heteroscedasticity. Econometrica, 48(4), pp. 817-838.

Yoon, J. W., Kim, J. and Lee, J. (2014). Impact of Demographic Changes on Inflation and the Macroeconomy. IMF Working Paper, N 14/210. 